\title{
Influence of Annealing Temperature on Characteristics of Bismuth Doped Zinc Oxide Films
}

\author{
${ }^{1}$ Sirirat Tubsungnoen Rattanachan, ${ }^{1}$ Phanuwat Krongarrom and ${ }^{2}$ Thipwan Fangsuwannarak \\ ${ }^{1}$ School of Ceramic Engineering, Institute of Engineering, \\ ${ }^{2}$ School of Electrical Engineering, Institute of Engineering, \\ Suranaree University of Technology, 111 University Avenue, Nakhon Ratchasima 30000, Thailand
}

Received 2013-07-03, Revised 2013-08-28; Accepted 2013-10-01

\begin{abstract}
In this study, Bismuth (Bi) doped $\mathrm{ZnO}$ thin films were deposited on quartz substrates by a sol-gel spin coating method and annealed at different annealing temperatures of $200,300,400,500,600$ and $700^{\circ} \mathrm{C}$, respectively. Structural and optical properties of nanocrystalline Bi-doped $\mathrm{ZnO}$ film on quartz were investigated by using X-Ray Diffraction (XRD), Scanning Electron Microscope (SEM) and UV-VIS spectrophotometer. The high annealing temperature of $700^{\circ} \mathrm{C}$ as a critical temperature causes the crystallographic reorientation plane in $\mathrm{ZnO}: \mathrm{Bi}$ nanostructure mostly due to the initial formation of the polycrystalline phase with the inter-grain segregation of $\mathrm{Bi}$ dopant atoms. Bi-incorporating $\mathrm{ZnO}$ films with an increase in annealing temperature resulted in a blue wavelength shift of the photon absorption edge. The optical band gap of the films was increased from $3.27 \mathrm{eV}$ to $3.34 \mathrm{eV}$. By decreasing the annealing temperatures from 700 to $200^{\circ} \mathrm{C}$, the grain size of Bi-doped $\mathrm{ZnO}$ decreased from $18 \mathrm{~nm}$ to $8 \mathrm{~nm}$. The effect of the annealing temperature on the electrical conductivity had been considered. The low electrical conductivity of $0.9(\Omega . \mathrm{cm})^{-1}$ was obtained for $\mathrm{ZnO}: 0.2$ film annealed at $600^{\circ} \mathrm{C}$ with good nano-crystallization. However, the Bi-doped $\mathrm{ZnO}$ films prepared by cost-effective spin coating technique provided to have a very high photon absorption coefficient $\left(10^{4}-10^{5} \mathrm{~cm}^{-1}\right)$ and did not appreciably affect the optical transparency. $\mathrm{ZnO}$ films doped with $0.2 \%$ at. Bi can be used as a high resistive buffer layer for solar cell application.
\end{abstract}

Keywords: Zinc Oxide, Nanostructure, Bismuth Doping, Sol-Gel Technique, Thin Film, Solar Cells

\section{INTRODUCTION}

Zinc Oxide $(\mathrm{ZnO})$ thin film is a direct energy band gap of 3.2-3.3 eV at room temperature. Due to its features such as good optical transparency in the visible wavelength range, the values of electrical resistance in the wide range of $10^{-4}-10^{12} \Omega . \mathrm{cm}$. Bahsi and Oral (2007) and environmental stability, $\mathrm{ZnO}$ is widely applied as a transparent conductive electrode, an electron selective layer (Cheng et al., 2012) and a window layer in electronic and optoelectronic applications. Moreover, a structural characteristic of the $\mathrm{ZnO}$ films as the highly preferential orientation along the c-axis is useful in surface acoustic wave, acoustic optic and optical wave-guide devices (Chen et al., 2010).

In a role of anti-reflection coating layer for photovoltaic application, nanostructured $\mathrm{ZnO}$ exhibits an excellent surface texture and can improve the solar cell short circuit current to $5.7 \%$ (Ae et al., 2010). The textured $\mathrm{ZnO}$ layer showed an effective light trapping property but the films required a high deposition temperature (Wang et al., 2012). In addition, with a changing optical band gap of nanocrystalline $\mathrm{ZnO}(\mathrm{NC}-$ $\mathrm{ZnO}$ ), the different band gaps of the active $\mathrm{NC}-\mathrm{ZnO}$ layers give rise to a utilization of wide range of the solar spectrum for the development in tandem cell structure of

Corresponding Author: Sirirat Tubsungnoen Rattanachan, School of Ceramic Engineering, Institute of Engineering,

Suranaree University of Technology, 111 University Avenue, Nakhon Ratchasima 30000, Thailand Tel: +66-44-224475 Fax: +66-44-224612 
thin film and polymer solar cells (Park et al., 2009). $\mathrm{ZnO}$ was reported to have an important role of a highly resistive buffer layer in power conversion improvement for the $\mathrm{Cu}(\mathrm{In}, \mathrm{Ga}) \mathrm{Se}_{2}$ and the organic solar cells (Park et al., 2009). The increasing resistance in the shunt $\mathrm{ZnO}$ path has been investigated in order to decrease the current leakage. By incorporating the highly resistive $\mathrm{ZnO}$, the thin film solar cells showed a $16 \%$ efficiency.

$\mathrm{ZnO}$ nanostructures can be synthesized by several methods such as sol-gel (Ng et al., 2012), hydrothermal synthesis (Schlur et al., 2013), thermal deposition, plasma (Zhang et al., 2013) or sputtering (Zhang et al., 2011). Almost all the prepared $\mathrm{ZnO}$ films were shown to be highly conductive and transparent $\mathrm{ZnO}$ films because of a main approach to transparent electrode. Among these preparation methods, sol-gel coating process is an attractive technique for obtaining $\mathrm{ZnO}$ nanostructure owing to the easy control of the film composition and low-cost fabrication of large-area films.

Bismuth has been an important dopant in $\mathrm{ZnO}$. With a small amount of $\mathrm{Bi}$, the $\mathrm{ZnO}$ film exhibits a double Schottky barrier characteristic, which is applied in the fabrication of varistors (Schloffer et al., 2010). It is known that when $\mathrm{Bi}$ dopants have a high concentration level, $\mathrm{ZnO}-\mathrm{Bi}_{2} \mathrm{O}_{3}$ binary system that is formed exhibits nonlinear current-voltage characteristic. Bi-doped $\mathrm{ZnO}$ films (denoted as $\mathrm{ZnO}: \mathrm{Bi})$ were deposited by using RF magnetron sputtering (Jiang et al., 2009). They reported that the film annealed at $400^{\circ} \mathrm{C}$ had the lowest electrical resistivity $\left(1.89 \times 10^{-3} \Omega . \mathrm{cm}\right)$, high carrier density $\left(3.45 \times 10^{20} \mathrm{~cm}^{-3}\right)$ and good transmittance in visible wavelength region. According to Bi-doped $\mathrm{ZnO}$ films prepared by molecular-beam epitaxy (MBE), the Hall effect measurements revealed a dramatic reduction of electron density with the increase of $\mathrm{Bi}$ incorporation (Xiu et al., 2006). Thus, an increase of the resistivity, the carrier types and the density of $\mathrm{ZnO}$ : $\mathrm{Bi}$ film depended on $\mathrm{Bi}$ concentration mainly due to the defect complexes from highly doping $\mathrm{Bi}$ atoms acting as acceptors (Lee et al., 2011). However, the basic electrical properties of $\mathrm{ZnO}$ :Bi thin film have not been clarified.

In our previous report, $\mathrm{ZnO}$ doped with $0.2-1.0$ at $\%$ Bi films which were highly textured along the c-axis have been successfully deposited on quartz substrates by sol-gel spin-coating technique (Krongarrom et al., 2012). In the present study, the effect of annealing temperatures on the structural, optical and electrical properties of $\mathrm{Bi}$-doped $\mathrm{ZnO}$ films was investigated. The purpose of this study is to investigate the evolution of the optical and electrical properties of $\mathrm{ZnO}: \mathrm{Bi}$ nanostructure with annealing conditions, concerning the effectiveness of $\mathrm{Bi}$ incorporation in particular. The current-voltage characteristic of $\mathrm{ZnO}: \mathrm{Bi}$ films and its dependence on the strain along the c-axis and crystal quality are also discussed.

\section{MATERIALS AND METHODS}

\subsection{Precursor Preparation}

$\mathrm{ZnO}: \mathrm{Bi}$ solution was prepared from zinc acetate dihydrate (Ajax Finechem) and Bismuth nitrate pentahydrate 1_(Fluka) used as starting chemicals. The $0.7 \mathrm{M} \mathrm{ZnO}$ precursor solution was prepared by dissolving zinc acetate dehydrate in ethylene glycol $(99.5 \%$, CARLO ERBA). Monoethanolamine (MEA, 97.0\%, Ajax Finechem) was chosen as a stabilizer. The molar ratio of $\mathrm{Zn}$ :MEA was kept at 1.0. The preparation process of $\mathrm{ZnO}$ and $\mathrm{ZnO}$ :Bi films based on spin coating technique was detailed in the previous work (Krongarrom et al., 2012). The mixture was stirred at $80^{\circ} \mathrm{C}$ for $10 \mathrm{~min}$. Subsequently, $0.125 \mathrm{M}$ of bismuth nitrate pentahydrate as a doping source was added in the starting solution. The doping level was varied by changing the atomic ratio $[\mathrm{Bi} / \mathrm{Zn}]$ in the solution from 0 to $6.0 \mathrm{at} \%$. A clear solution was obtained during the process of stirring for 1 hour at $80^{\circ} \mathrm{C}$.

\subsection{Film Deposition}

The quartz substrates were carefully cleaned by the Ratio Corporation of America (RCA) process. The substrates were soaked in a solution of $30 \% \mathrm{H}_{2} \mathrm{O}_{2}: 28$ $30 \% \mathrm{NH}_{4} \mathrm{OH}$ : DI-water in volume ratio of $1: 1: 5$ at $70^{\circ} \mathrm{C}$ for $10 \mathrm{~min}$ and then rinsed with DI water for $10 \mathrm{~min}$ before drying with nitrogen gas flow. To remove the metal contamination, the substrates were soaked in a solution of $30 \% \mathrm{H}_{2} \mathrm{O}_{2}: 36.5-38 \% \mathrm{HCl}$ : DI-water of $1: 1: 5$ volume ratios at $70^{\circ} \mathrm{C}$ for $10 \mathrm{~min}$ and then rinsed with DI water for $10 \mathrm{~min}$ before drying with nitrogen gas flow. After aging the gel at room temperature for $24 \mathrm{~h}$, the gel was coated on a cleaned quartz substrate. The atomic percentage of $\mathrm{Bi}$ dopant in $\mathrm{ZnO}$ solution were $0,0.2,0.4$, $0.6,1.0,1.2,2.0,4.0$ and 6.0 at\%, denoted as $\mathrm{ZnO}$ and $\mathrm{ZnO}: \mathrm{xBi}$ ( $\mathrm{x}=$ at.\% $\mathrm{Bi}$ doping). The $\mathrm{ZnO}: \mathrm{xBi}$ films were prepared by using the spin coating technique at $2500 \mathrm{rpm}$ for $10 \mathrm{sec}$. The thin films were pre-baked at $100^{\circ} \mathrm{C}$ for $30 \mathrm{~min}$ in an oven. The coating and preheating treatment processes were repeated 5 times to obtain the thickness of the as-deposited film at about $443 \mathrm{~nm}$. 
The influence of different annealing conditions on the properties of $\mathrm{ZnO}: \mathrm{Bi}$ nanostructure was studied. In this study, undoped $\mathrm{ZnO}$ and $\mathrm{ZnO}: \mathrm{xBi}$ films were annealed by varying the annealing temperatures from 200 to $700^{\circ} \mathrm{C}$ in the ambient air for $2 \mathrm{~h}$. This temperature range was considered since the nanoparticles generally require a lower melting temperature than in a bulk form. The film thickness was decreased from 362 to $243 \mathrm{~nm}$ after annealing from 200 to $700^{\circ} \mathrm{C}$.

The X-ray diffractometer (RIGAKU TTRAX III) was used to examine the crystalline quality of all samples with a $\mathrm{Cu}-\mathrm{K} \alpha$ radiation $(\lambda=1.54059 \AA)$. The crystalline grain size has been calculated from XRD data using Scherrer's formula. The surface morphology was observed using a JEOL JSM-6400 Scanning Electron Microscope (SEM) operating at $12 \mathrm{kV}$. The thickness of the films was measured by an optical profiler (Veeco WYKO NT1100). The optical absorbance of the films was verified by a UV-VIS spectrophotometer (AJUK SPECORD 250+222P133) in the wavelength range from 300 to $1100 \mathrm{~nm}$. For the transmittance and reflectance measurements, the optical spectra of all samples were compensated by those of the quartz substrate. The optical band gap Energy $\left(\mathrm{E}_{\mathrm{g}}\right)$ was obtained by extrapolating the high absorption region of the curve to the energy axis. The current-voltage characteristic of $\mathrm{ZnO}$ :xBi films was conducted with using 2-point probe arrangement under a shielded metal box with co-axial wires to ensure elimination of noise and obtain stability. Silver paste was used as contact metal with the diameter size of around 1 mm. 2-point Ag contact was prepared with around $1 \mathrm{~mm}$ interval and then it was fired at $200^{\circ} \mathrm{C}$ for $30 \mathrm{~min}$ in order to behave as an Ohmic contact.

\section{RESULTS}

\subsection{Structural Characterizations}

\subsubsection{Effect of Bi Doping}

Figure 1 illustrates the XRD patterns of undoped $\mathrm{ZnO}$ and $\mathrm{ZnO}: \mathrm{xBi}$ thin films with different $\mathrm{Bi}$ doping concentration in the range of 0.2-6.0 at.\%. All films were annealed at $600^{\circ} \mathrm{C}$ for $2 \mathrm{~h}$. The results obvious that XRD pattern of undoped $\mathrm{ZnO}$ shows the diffraction peaks of polycrystalline $\mathrm{ZnO}$ as JCPD card 36-1451.

For other $\mathrm{ZnO}: \mathrm{xBi}$ with low $\mathrm{x}$-composition ranges between 0.2 and 1.0 at.\%, it is found that there is only (002) diffraction peak of wurtzite to dominate in the XRD patterns. The results show that these films exhibit a relatively high-preferential orientation along the c-axis and imply to the effectiveness of $\mathrm{Bi}$ incorporation. For $\mathrm{ZnO}: \mathrm{xBi}$ films with $\mathrm{x}$-composition range between 6.0 and 1.2 at.\%, it presents the diffraction peaks of polycrystalline $\mathrm{ZnO}$ at (100), (002), (101), (102), 110 and 103 planes (JCPD card 36-1451) which are similar to undoped $\mathrm{ZnO}$ film.

By comparing the $\mathrm{ZnO}: \mathrm{Bi}$ films at different $\mathrm{Bi}$ concentrations, the relative intensity $\mathrm{I}_{(002)} /\left[\mathrm{I}_{(002)}+\mathrm{I}_{(101)}+\mathrm{I}_{(103)}\right]$, the strain along the c-axis and the full width half maximum of (002) spectrum are shown in Fig. 2a-c respectively. For low doping concentration, the (002) peak relative intensity initially increases and then turns to decrease for $\mathrm{Bi}$ dopant above 1.0 at\%., as shown in Fig. 2a.

To determine the strain along the c-axis for thin films, the results from XRD data were calculated by the following Equation (1):

$$
\varepsilon=\frac{\mathrm{C}-\mathrm{C}_{0}}{\mathrm{C}_{0}} \times 100
$$

Where:

$\mathrm{C}=$ The lattice parameter of the film with dopant calculated from XRD data

$\mathrm{C}_{0}=$ The lattice parameter of undoped $\mathrm{ZnO}$ crystal $\left(\mathrm{C}_{0}\right.$ $=5.217$ )

In Fig. 2b, the strain along the c-axis for $\mathrm{ZnO}: \mathrm{xBi}(\mathrm{x}=$ 0.2-1.0 at.\%) exhibits a positive sign (tensile). The minimum strain along the c-axis presents the tensile behavior for $\mathrm{ZnO}: 1.2 \mathrm{Bi}$ film. It may imply a critical value for the initial $\mathrm{Bi}_{2} \mathrm{O}_{3}$ phase segregation which is associated with the maximum FWHM value in XRD data as shown in Fig. 2c. At the higher Bi doping level, the strain along the $\mathrm{c}$-axis changes to a negative sign (compressive) which is relevant to the existence of $\mathrm{Bi}_{2} \mathrm{O}_{3}$ phase.

\subsubsection{Effect of The Annealing Temperature}

According to the maximum relative intensity of (002) peak and low tensile behavior along the c-axis, 0.2 at. $\%$ Bi doping level is the optimum $\mathrm{Bi}$ concentration in a sol-gel synthesis. In order to investigate the effect of heat-treatment on crystallographic orientation and surface morphology, the annealing temperature of preferential $\mathrm{ZnO}: 0.2 \mathrm{Bi}$ films were elevated in the range of $200-700^{\circ} \mathrm{C}$. It is found that there is a dominating (002) diffraction peak in the XRD patterns for all of the films except for the film annealed at $700^{\circ} \mathrm{C}$, as can be seen in Fig. 3 . 
Sirirat Tubsungnoen Rattanachan et al. / American Journal of Applied Sciences 10 (11): 1427-1438, 2013

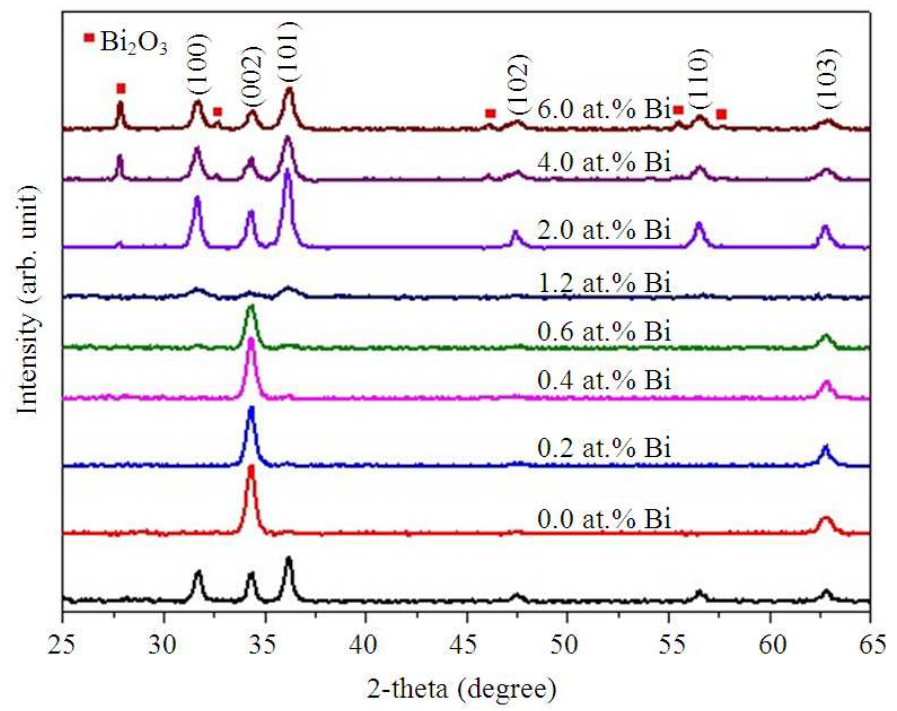

Fig. 1. $\mathrm{XRD}$ patterns of $\mathrm{ZnO}: \mathrm{xBi}$ thin films annealed at $600^{\circ} \mathrm{C}$ with varying $\mathrm{Bi}$ doping concentrations

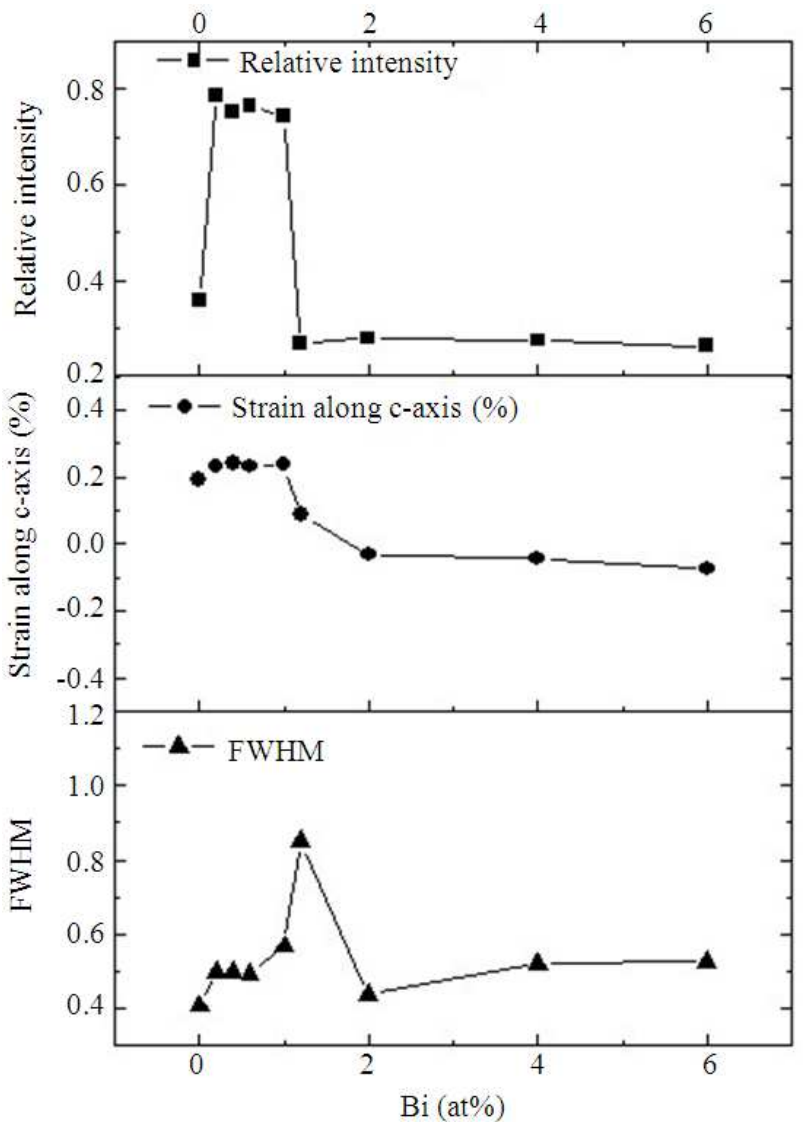

Fig. 2. Relationship between the Bi doping concentration and (a) the relative intensity of (002) peak, (b) stain along the c-axis and (c) full width at half maximum (FWHM) of (002) peak from XRD data 


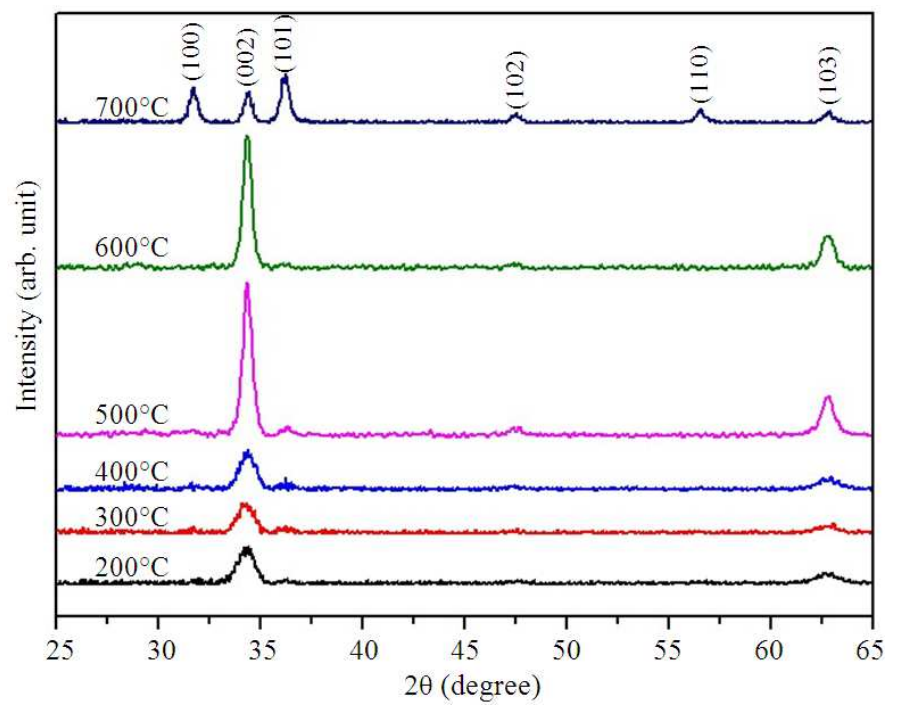

Fig. 3. XRD patterns of $\mathrm{ZnO}: 0.2 \mathrm{Bi}$ thin films annealed at different annealing temperatures

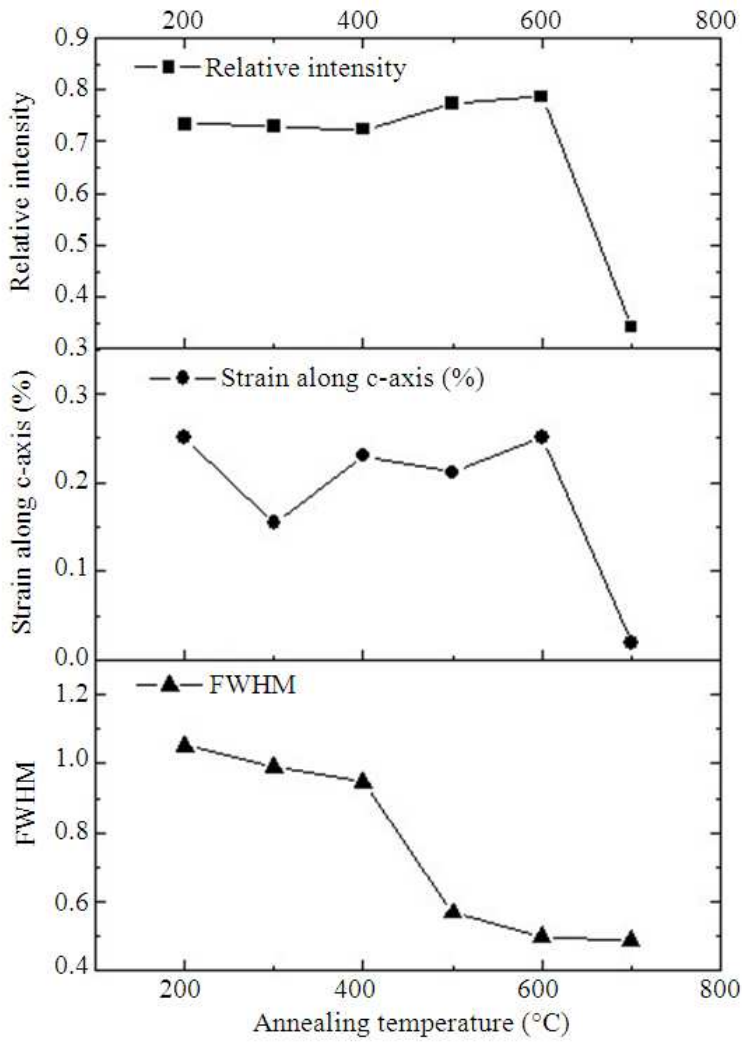

Fig. 4. Relationship between the annealing temperature and (a) the relative intensity of (002) peak, (b) stain along the c-axis and (c) full width at half maximum (FWHM) of (002) peak from XRD data
It is noted that the presence of dominating (002) diffraction peak revealed the highly orientated crystallographic growth of $\mathrm{ZnO}$ : $0.2 \mathrm{Bi}$ films with c-axis perpendicular to substrates.

Furthermore, the maximum relative intensity with the minimum FWHM was obtained for the film annealed at $600^{\circ} \mathrm{C}$ (Fig. 4a and c). The results can be interpreted as the improvement of crystallinity and the diminished disorder in the crystal lattice owing to the incorporation of the $\mathrm{Bi}$ ions into $\mathrm{ZnO}: 0.2 \mathrm{Bi}$ film. On the other hand, the XRD pattern for the films annealed at $700^{\circ} \mathrm{C}$ evolved from (002)-peak dominance to (101)-peak dominance. Meanwhile, the diffraction relative intensity is remarkably lower than that for others, as shown in Fig. 4a. This result is relevant to a drop of the strain along the c-axis, as illustrated in Fig. 4b. A decrease in the tensile suggests $\mathrm{Bi}$ phase segregation and/or surface segregation for $\mathrm{ZnO}: 0.2 \mathrm{Bi}$ film annealed at $700^{\circ} \mathrm{C}$. The average crystal size (d) of the Bi-doped $\mathrm{ZnO}$ films was estimated from the XRD pattern according to the Scherrer's relation Equation (2):

$\mathrm{d}=\frac{0.9 \lambda}{\mathrm{B} \cos \theta_{\mathrm{B}}}$

Where:

$\lambda=$ The X-ray radiation wavelength $(0.154 \mathrm{~nm})$

$\theta_{\mathrm{B}}=$ The Bragg diffraction angle of XRD peak

$\mathrm{B}=$ The Full Width at Half Maximum (FWHM) 


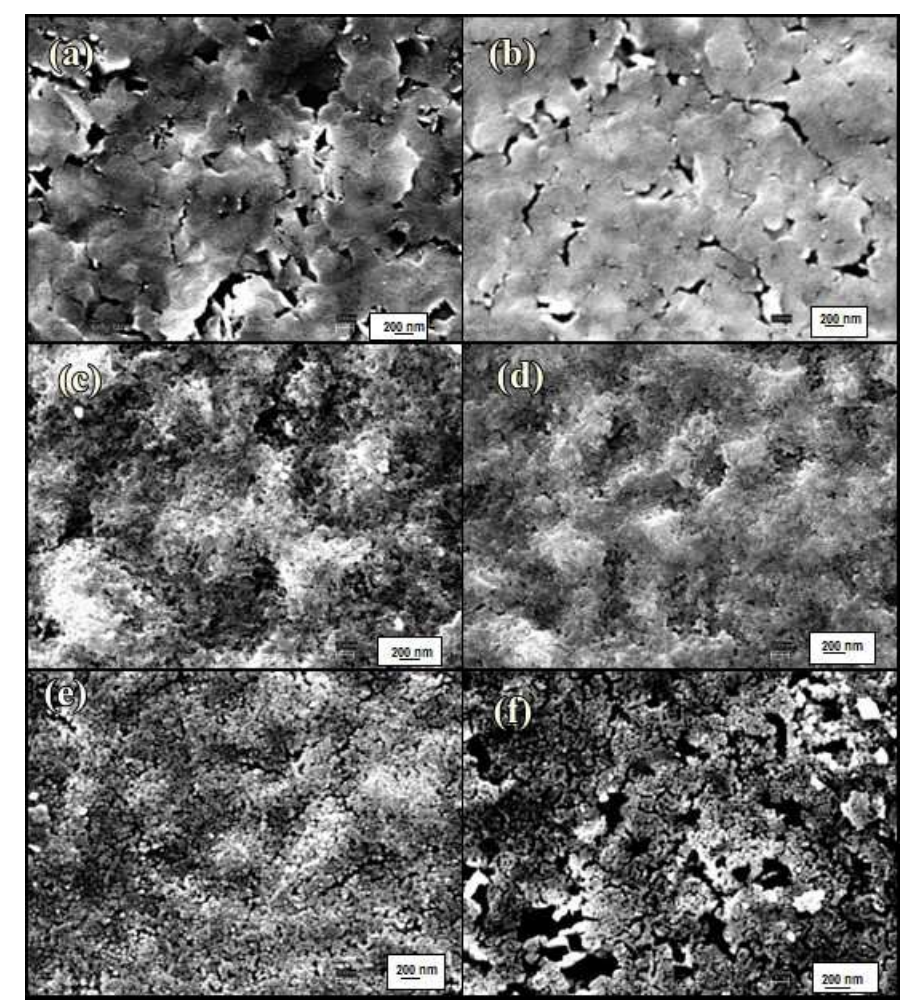

Fig. 5. SEM micrographs of ZnO:0.2Bi thin films annealed at (a) $200^{\circ} \mathrm{C}$, (b) $300^{\circ} \mathrm{C}$, (c) $400^{\circ} \mathrm{C}$, (d) $500^{\circ} \mathrm{C}$, (e) $600^{\circ} \mathrm{C}$ and (f) $700^{\circ} \mathrm{C}$

The estimated nanocrystalline size of $\mathrm{ZnO}: 0.2 \mathrm{Bi}$ films varying from 7.9 to $17.7 \mathrm{~nm}$ is exhibited, relating to the increase of the annealing temperature from 200 to $700^{\circ} \mathrm{C}$. The result revealed that the quality of crystalline lattice and the effective of $\mathrm{Bi}$ incorporation into $\mathrm{ZnO}: 0.2 \mathrm{Bi}$ films were significantly improved by increasing the annealing temperatures from 200 to $600^{\circ} \mathrm{C}$.

The surface morphologies of all films as a function of annealing temperature ranging from 200 to $700^{\circ} \mathrm{C}$ were observed by using a scanning electron microscope as shown in Fig. 5. At the lower annealing temperatures, many large cracks in SEM images as shown in Fig. 5 a-b, appear on the surface of $\mathrm{ZnO}: 0.2$ Bi film. Meanwhile, at the higher annealing temperatures, the surface morphology of the film became more uniform. However, heat-treatment at $700^{\circ} \mathrm{C}$ affected the film surface in that it becomes less uniform with existence of coalescence of the grains as shown in Fig. 5f. Thus, the optimized annealing between 400 and $600^{\circ} \mathrm{C}$ results in the good quality of the film surface and the further essential attributes for Bi-doped $\mathrm{ZnO}$ devices.

\subsection{Optical Properties}

All films show the high average transmittance exceeding $85 \%$ in the visible wavelength range (400-800 $\mathrm{nm})$. In this study, the optical transmittance spectra of $\mathrm{ZnO}: 0.2 \mathrm{Bi}$ thin films as the function of the annealing temperatures are shown in Fig. 6. After annealing, the average transmittance in the visible range of the films is higher than that of as-deposited film, whereas the asdeposited film has the average transmittance above others in the UV range. The films annealed at low temperatures $\left(200-300^{\circ} \mathrm{C}\right)$ exhibit the average transmittance in visible wavelengths above the films annealed at the higher temperatures $\left(400-700^{\circ} \mathrm{C}\right)$.

The photon absorption coefficient $(\alpha)$ of $\mathrm{ZnO}$ :Bi films is shown in Fig. 7, which is determined by transmission measurement. Shallow-level impurities respond much more effectively to optical measurements and are usually measured by optical absorption measurements. The absorption coefficient $(\alpha)$ is defined by Equation (3):

$$
\alpha=\frac{1}{\mathrm{~d}} \ln \left(\frac{\sqrt{(1-\mathrm{R})^{4}+\mathrm{T}^{2} \mathrm{R}^{2}}-(1-\mathrm{R})^{2}}{2 \mathrm{TR}^{2}}\right)
$$


Sirirat Tubsungnoen Rattanachan et al. / American Journal of Applied Sciences 10 (11): 1427-1438, 2013

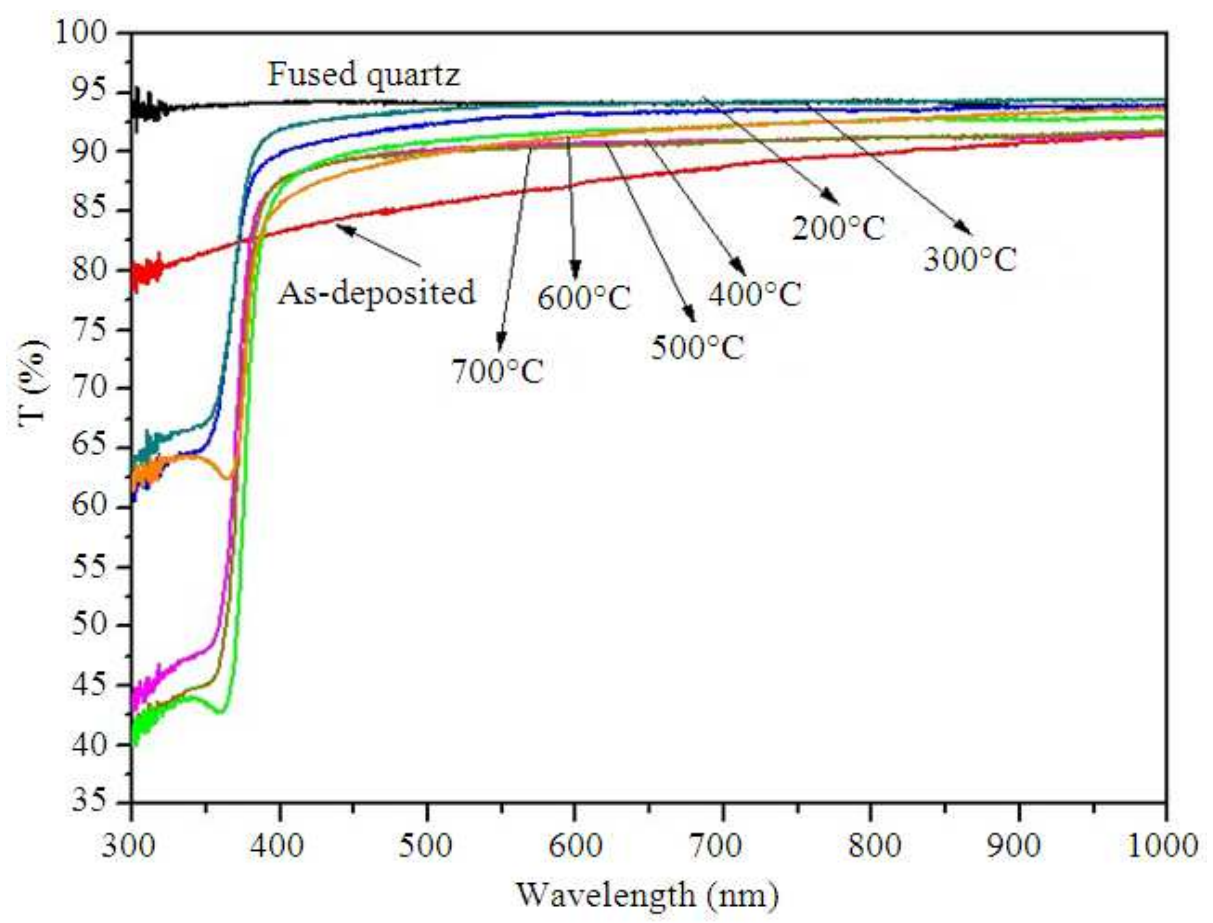

Fig. 6. The transmittance spectra in UV-Vis wavelength range between 400 and $1000 \mathrm{~cm}^{-1}$ of $\mathrm{ZnO} 0.2 \mathrm{Bi}$ films with different annealing temperatures

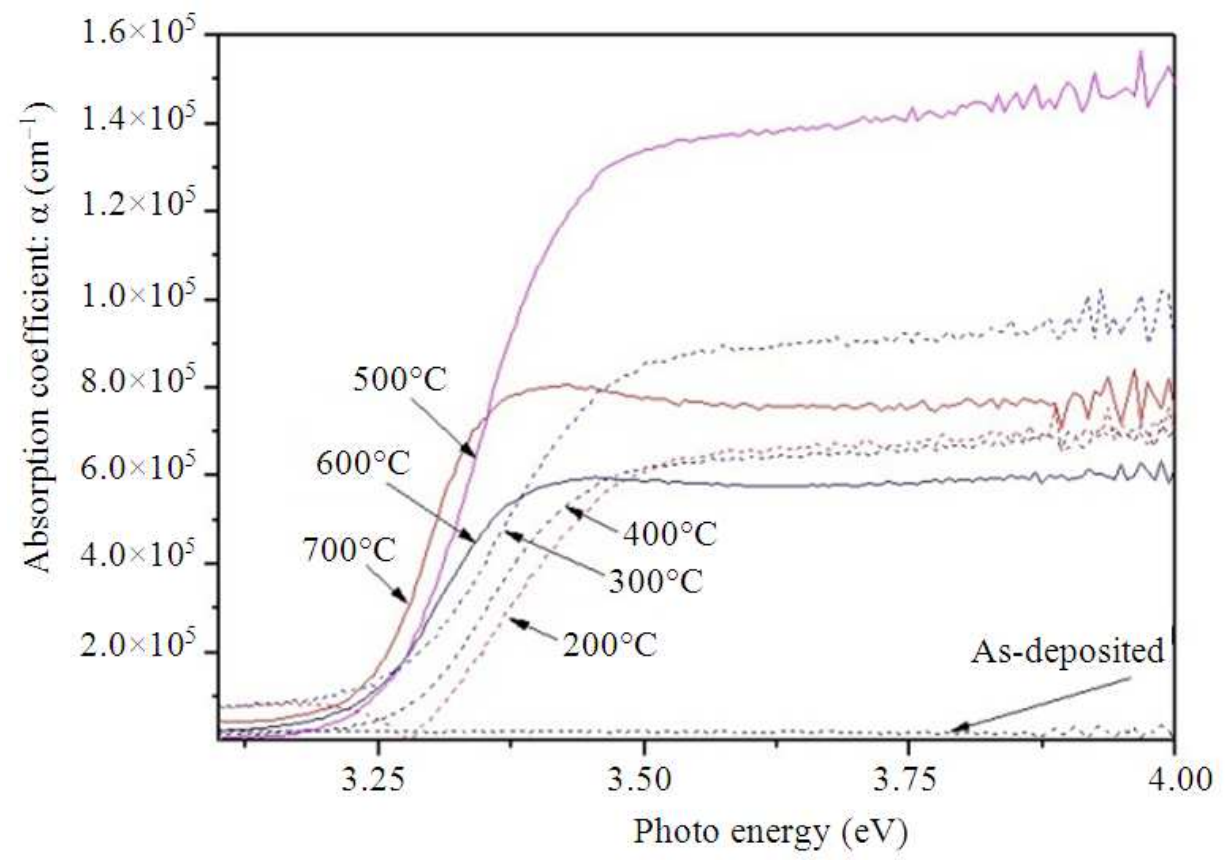

Fig. 7. The relationship between the absorption coefficient and photon energy of $\mathrm{ZnO}$ : $0.2 \mathrm{Bi}$ films annealed at various annealing temperatures 
Where:

$\mathrm{d} \quad=$ The thickness of the film $(\mu \mathrm{m})$

$\mathrm{R}$ and $\mathrm{T}=\mathrm{The}$ reflectance and transmittance, respectively

Figure 7 shows the very high absorption coefficient up to $10^{5} \mathrm{~cm}^{-1}$ and it is found to increase rapidly with an increase in photon energy.

For a direct band gap semiconductor such as $\mathrm{ZnO}$, the optical band gap $\left(\mathrm{E}_{\mathrm{g}}\right)$ can be determined from transmittance and reflectance measurements. $\mathrm{E}_{\mathrm{g}}$ can be estimated by an extrapolation of the linear curve portion as a function of absorption coefficient $(\alpha)$ dependent on photon energy (hv) Equation (4):

$$
\alpha(h v)=C\left(h v-E_{g}\right)^{\frac{1}{2}}
$$

Where:

$C=$ a constant for a direct transition of photon energy of

$$
2.4 \times 10^{4}
$$

The variations of $\alpha^{2}$ versus hv in the fundamental adsorption region are plotted in Fig. 8. By decreasing the annealing temperatures from $600^{\circ} \mathrm{C}$ to $200^{\circ} \mathrm{C}$, the absorption edge shifted towards the shorter wavelength side from $3.27 \mathrm{eV}$ to $3.34 \mathrm{eV}$ as compared with an undoped $\mathrm{ZnO}$ film. The results of $\mathrm{E}_{\mathrm{g}}$ extension in this study are related to the decrease in the crystalline grain size from about 18 to $8 \mathrm{~nm}$ as illustrated in Fig. 9.

\subsection{Electrical Properties}

Figure 10 shows the evolution of the electrical conductivity under illumination $\left(18 \mathrm{~mW} / \mathrm{cm}^{2}\right)$ at room temperature of $\mathrm{ZnO}: 0.2 \mathrm{Bi}$ films with different annealing temperatures. Inset in Fig. 10 shows the difference between the photocurrent obtained by measuring the I-V curve under dark condition and under illumination of $\mathrm{ZnO}$ : $0.2 \mathrm{Bi}$ films with various annealing conditions.

All samples indicate good Ohmic contact behavior. Therefore, the electrical conductivity $(\sigma)$ was calculated by $\sigma=\mathrm{L} /(\mathrm{R} . \mathrm{A})$, where $\mathrm{L}$ is the contact distance, $R$ is the resistance value from 1 /slope value of $\mathrm{I}-\mathrm{V}$ curve, $\mathrm{A}$ is the film thickness by the diameter size of metal contact. It was found that the electrical conductivity under illumination condition was enhanced due to the presence of photocurrent as compared with the one under dark condition. At $600^{\circ} \mathrm{C}$ annealing condition, the conductivity enhances with the increase in annealing temperature and reaching the maximum value at $0.9(\Omega . \mathrm{cm} .)^{-1}$. However, the film heated at $700^{\circ} \mathrm{C}$ shows the decrease of the conductivity corresponding to the rapid decrease of the relative intensity and the strain along the c-axis which is due to crystallographic reorientation.

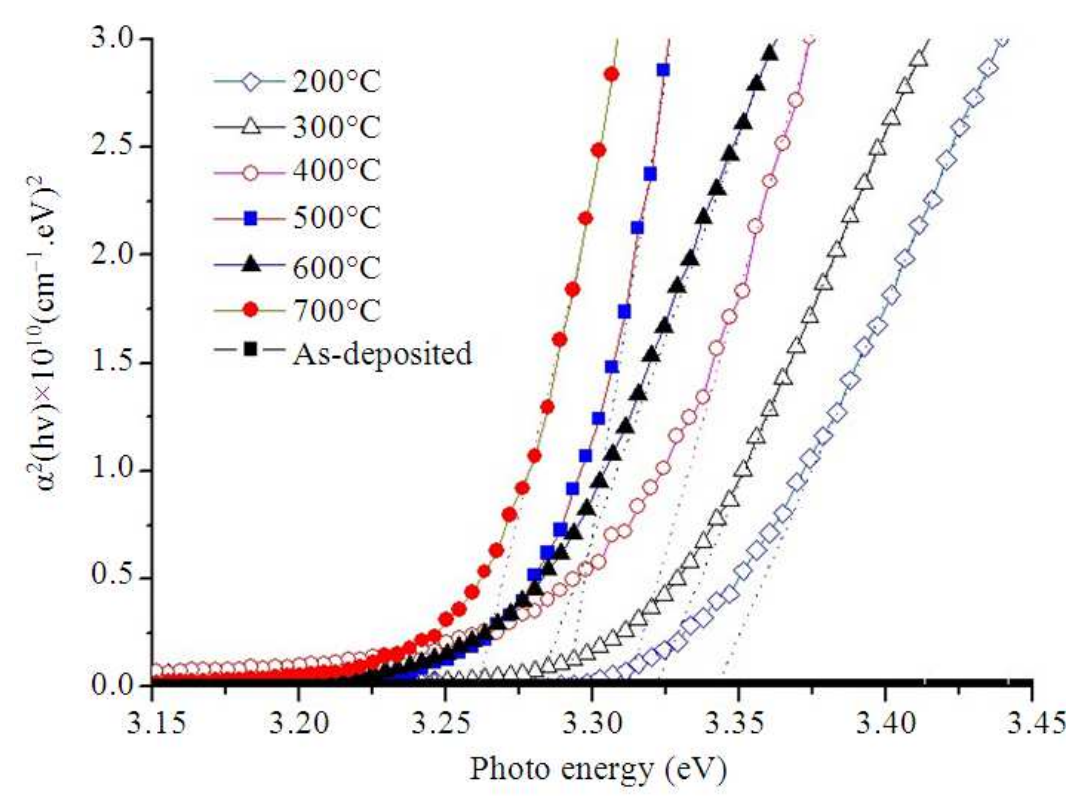

Fig. 8. $(\alpha h v)^{2}$ versus $(h v)$ curves of $\mathrm{ZnO}$ : $0.2 \mathrm{Bi}$ thin films annealed with various temperatures 
Sirirat Tubsungnoen Rattanachan et al. / American Journal of Applied Sciences 10 (11): 1427-1438, 2013

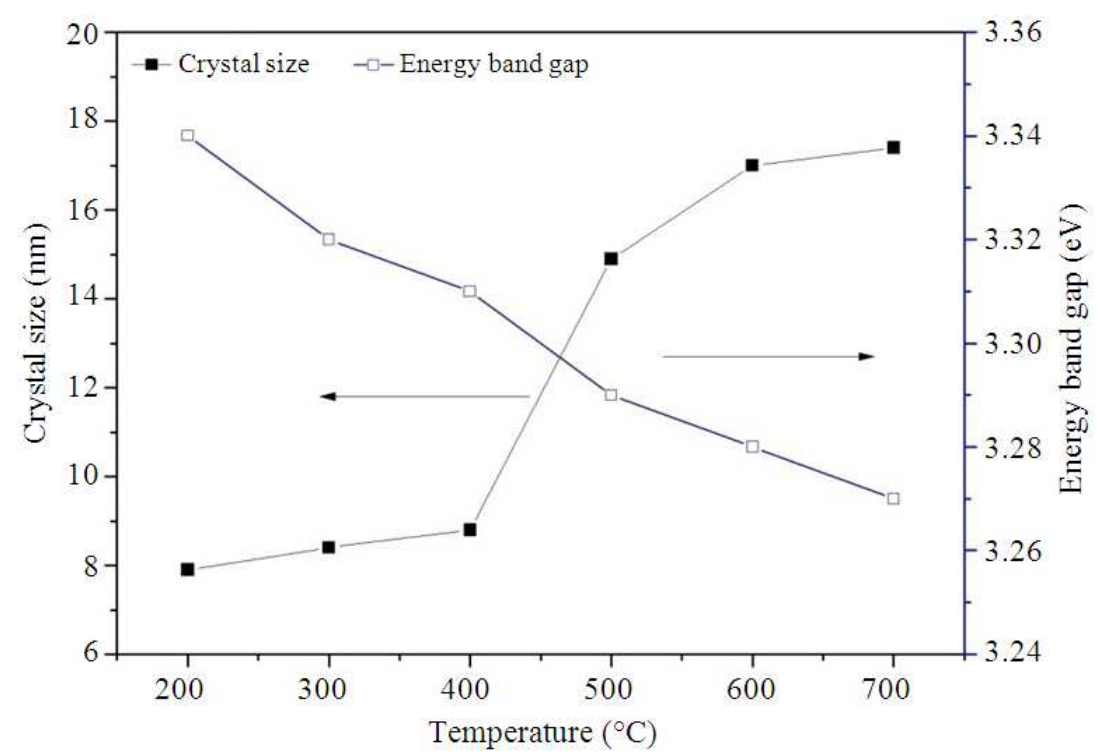

Fig. 9. Variation of average crystal size and energy bang gap of $\mathrm{ZnO}: 0.2 \mathrm{Bi}$ samples as a function of the annealing temperature

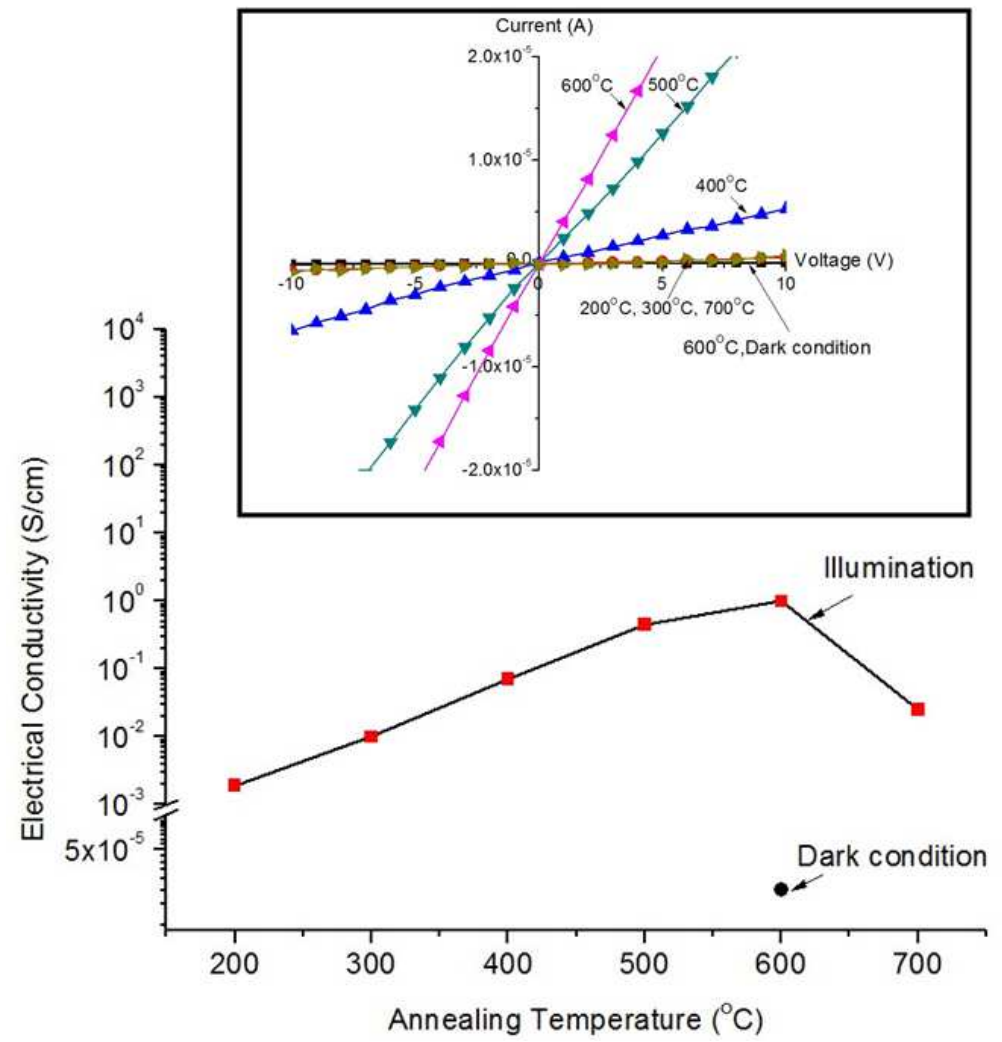

Fig. 10. The relation of the electrical conductivity of $\mathrm{ZnO}: 0.2 \mathrm{Bi}$ film and the annealing temperature. The insert showing the $\mathrm{I}-\mathrm{V}$ curves as a function of annealing temperature 


\section{DISCUSSION}

The XRD results is noticed that the peak positions at $2^{\circ}$ of $27.94^{\circ}, 32.69^{\circ}, 46.20^{\circ}, 55.49^{\circ}$ and $57.75^{\circ}$ observed for $\mathrm{ZnO}$ : $\mathrm{xBi}\left(\mathrm{x}>2.0\right.$ at.\%) samples were indicated $\mathrm{Bi}_{2} \mathrm{O}_{3}$ phases. This can be interpreted in the terms of greater segregation of doping components at the grain boundaries due to the high doping content as reported in the previous work (Krongarrom et al., 2012). Concerning the effectiveness of $\mathrm{Bi}$ incorporation in $\mathrm{ZnO}$, the $\mathrm{Bi}_{2} \mathrm{O}_{3}$ phase separation and/or surface separation in $\mathrm{ZnO}: \mathrm{Bi}$ films need to be diminished in order to avoid fuzzy carrier types. Therefore, in this study, the case of low Bi doped $\mathrm{ZnO}$ was much of greatest concerned.

The results of the relative intensity and the stain can confirm the highly preferential orientation along the caxis for low $\mathrm{Bi}$ doped $\mathrm{ZnO}$ films. It could be attributed to the formation of new nucleating centers due to the doping atoms (Oztas and Bedir, 2008). The preferential orientation of the (002) plane is related to the minimization of the surface energy while the subsequent decrease of the (002) peak relative intensity for higher doping concentration can be affected by the saturation of newer nucleating centers ( $\mathrm{Li}$ et al., 2010; 2011). The trend of decrease in relative intensity of (002) peak with increasing in doping content is similar to the study of previous work (Caglar, 2013).

The result of a drop of the strain is noted that annealing temperature at $700^{\circ} \mathrm{C}$ as a critical temperature for the film causes the crystallographic reorientation which is changed into the polycrystalline structure as similar to the undoped sample. A similar result was also reported by others ( $\mathrm{Li}$ et al., 2010). Moroever, the increase in the annealing temperatures causes the atoms to receive a more diffuse activation energy and then to migrate into the energetically favorable site in the crystal lattice. This can lead eventually to the formation of the $\mathrm{Bi}_{2} \mathrm{O}_{3}$ phase segregation.

Bi doping levels below 1.0 at.\% do not significantly affect the optical transparency (Krongarrom et al., 2012), which is in agreement with the optical results of Bi-doped $\mathrm{ZnO}$ films prepared by rf. Magnetron sputtering technique (Karthikeyan et al., 2009). In this work, the decreasing tendency of the optical transmittance with the increase in the annealing temperature was similar to the previous reports for the undoped $\mathrm{ZnO}$ films (Karthikeyan et al., 2009).

In term of the optical property, the reduction of $E_{g}$ value with the increase of annealing temperature can be due to the improved crystallinity and the diminished defects of the films ( $\mathrm{Ng}$ et al., 2012). In addition, the effect of the annealing temperature on the $\mathrm{E}_{\mathrm{g}}$ of $\mathrm{ZnO} 0.2 \mathrm{Bi}$ films coincides with the study of Ga-doped $\mathrm{ZnO}$ film (Tsay et al., 2010). This is mainly due to the confinement regime. Therefore, it is suggested that the optical band gap of $\mathrm{ZnO}: 0.2 \mathrm{Bi}$ film was controllable by the annealing process.

The results of XRD and SEM is relevant to the enhancement in the conductivity of the films. It is suggested that highly orientated crystallographic growth and good morphology of $\mathrm{ZnO}: \mathrm{Bi}$ films are a good influence on their electrical properties. However, the caxis orientation growth is stronger as the annealing temperature increases and it is weaker after annealing at $700^{\circ} \mathrm{C}$. The annealing temperature optimized may benefit from the preferentially crystallographic reorientation in $\mathrm{ZnO}: \mathrm{Bi}$ nanostucture and it results in the improvement of the electrical conductivity. The trend of increasing electrical conductivity is similar to the previous work for $\mathrm{ZnO}$ film (Guillen and Herrero, 2010).

\section{CONCLUSION}

By using a sol-gel spin coating process, interstitial $\mathrm{Bi}$ impurities incorporated in the $\mathrm{ZnO}$ nanostructure were investigated under the different annealing temperatures $\left(200-700^{\circ} \mathrm{C}\right) . \quad \mathrm{XRD}$ results revealed the best crystallographic orientation with c-axis perpendicular to substrates for annealed $\mathrm{ZnO}: 0.2 \mathrm{Bi}$ film at $600^{\circ} \mathrm{C}$ as the optimal temperature. This optimal annealing condition leads to the increased effectiveness of electrical conductivity of $\mathrm{ZnO}: \mathrm{Bi}$ film which was verified by current-voltage measurement. However, the crystallographic reorientation pattern was found for $\mathrm{ZnO}: 0.2 \mathrm{Bi}$ film annealed at $700^{\circ} \mathrm{C}$ as a critical temperature which is relevant to the relative intensity and stain along c-axis values rapidly dropped. The origin of electrical conductivity and optical properties of sol-gel derived $\mathrm{ZnO}: \mathrm{Bi}$ films is verified as the combining effect of the different annealing temperatures. The effects of increasing heat-treatment temperature on the $\mathrm{E}_{\mathrm{g}}$ extension from $3.27 \mathrm{eV}$ to $3.34 \mathrm{eV}$ is related to the reduction of average grain size of $\mathrm{ZnO}: \mathrm{Bi}$ nanocrystal from 17.7 to 7.9 $\mathrm{nm}$ size. The low electrical conductivity of Bi-incorporating $\mathrm{ZnO}$ films with the preferentially crystallographic growth obtained can benefit its use as a dielectric buffer layer for thin film solar cells.

\section{ACKNOWLEDGMENT}

This study has been supported under the NANOTECH project no. NN.52-014 from National Nanotechnology Center, Thailand. The authors gratefully 
acknowledge the financial support of the National Research Council of Thailand for a graduate student grant and would like to express gratitude to the researchers from Photonics Technology Laboratory, MEMS and Nanoelectronics Laboratory and National Electronics and Computer Technology Center (NECTEC), Thailand for measurement support.

\section{REFERENCES}

Ae, L., D. Kieven, J. Chen, R. Klenk and T. Rissom et al., 2010. ZnO nanorod arrays as an antireflective coating for $\mathrm{Cu}(\mathrm{In}, \mathrm{Ga}) \mathrm{Se}_{2}$ thin film solar cells. Progress Photovoltaics: Res. Applic., 18: 209-213. DOI: 10.1002/pip.946

Bahsi, B.Z. and A.Y. Oral, 2007. Effects of $\mathrm{Mn}$ and $\mathrm{Cu}$ doping on the microstructures and optical properties of sol-gel derived $\mathrm{ZnO}$ thin films. Optical Mater., 29: 672-678. DOI: 10.1016/j.optmat.2005.11.016

Caglar, Y., 2013. Sol-gel derived nanostructure undoped and cobalt doped $\mathrm{ZnO}$ : Structural, optical and electrical studies. J. Alloys Compounds, 560: 181188. DOI: 10.1016/j.jallcom.2013.01.080.

Chen, C., Shi, B., Guo, L. and Zhao, M. 2010. A novel silica-waveguide acousto-optic frequency shifter using $\mathrm{ZnO}$ piezoelectric films and its beam propagation analysis. Proceedings of the SPIE, Optoelectronic Devices and Integration, Nov. 17-17, SPIE, pp: 78472J-78472J-8.

Cheng, G., W.Y. Tong, K.H. Low and C.M. Che, 2012. Thermal-annealing-free inverted polymer solar cells using $\mathrm{ZnO} / \mathrm{Cs}_{2} \mathrm{CO}_{3}$ bilayer as electron-selective layer. Solar Energy Mater. Solar Cells, 103: 164170. DOI: $10.1016 /$ j.solmat.2012.04.022

Guillen, C. and J. Herrero, 2010. Optical, electrical and structural characteristics of $\mathrm{Al}: \mathrm{ZnO}$ thin films with various thicknesses deposited by DC sputtering at room temperature and annealed in air or vacuum. Vacuum, $\quad 84$ : 924-929. DOI: 10.1016/j.vacuum.2009.12.015.

Jiang, M., X. Liu and H. Wang, 2009. Conductive and transparent $\mathrm{Bi}$-doped $\mathrm{ZnO}$ thin films prepared by $\mathrm{rf}$ magnetron sputtering. Surface Coatings Technol., 203: 3750-3753. DOI: 10.1016/j.surfcoat.2009.06.014

Karthikeyan, B., C.S.S. Sandeep, R. Philip and M.L. Baesso, 2009. Study of optical properties and effective three-photon absorption in Bi-doped $\mathrm{ZnO}$ nanoparticles. J. Applied Phys., 106: 114304.
Krongarrom, P., S.T. Rattanachan and T. Fangsuwannarak, 2012. ZnO doped with Bismuth in case of in-phase behavior for solar cell application. Eng. J., 16: 59-68. DOI: 10.4186/ej.2012.16.3

Lee, J.W., N.G.S., J.C. Lee, S.S. Kumar and T.W. Kang, 2011. Study of stable p-type conductivity in bismuth-doped $\mathrm{ZnO}$ films grown by pulsed-laser deposition. EPL, 95: 47002-47002. DOI: 10.1209/0295-5075/95/47002

Li, G., X. Zhu, H. Lei, W. Song and Z. Yang et al., 2010. Study on chemical solution deposition of aluminumdoped zinc oxide films. J. Alloys Compounds, 505: 434-442. DOI: 10.1016/j.jallcom.2010.06.083

Li, G., X. Zhu, X. Tang, W. Song and Z. Yang et al., 2011. Doping and annealing effects on $\mathrm{ZnO}$ : $\mathrm{Cd}$ thin films by sol-gel method. J. Alloys Compounds, 509: 4816-4823. DOI: 10.1016/j.jallcom.2011.01.176

Ng, Z.N., K.Y. Chan and T. Tohsophon, 2012. Effects of annealing temperature on $\mathrm{ZnO}$ and $\mathrm{AZO}$ films prepared by sol-gel technique. Applied Surface Sci., 258: 9604-9609. DOI: 10.1016/j.apsusc.2012.05.156

Oztas, M. and M. Bedir, 2008. Thickness dependence of structural, electrical and optical properties of sprayed $\mathrm{ZnO}: \mathrm{Cu}$ films. Thin Solid Films, 516: 1703-1709. DOI: 10.1016/j.tsf.2007.05.018

Park, S., S.J. Tark, J.S. Lee, H. Lim and D. Kim, 2009. Effects of intrinsic $\mathrm{ZnO}$ buffer layer based on P3HT/PCBM organic solar cells with Al-doped $\mathrm{ZnO}$ electrode. Solar Energy Mater. Solar Cells, 93: 1020-1023. DOI: 10.1016/j.solmat.2008.11.033

Schloffer, M., C. Teichert, P. Supancic, A. Andreev and Y. Hou et al., 2010. Electrical characterization of $\mathrm{ZnO}$ multilayer varistors on the nanometre scale with conductive atomic force microscopy. J. Eur. Ceramic Soc., 30: 1761-1764. DOI: 10.1016/j.jeurceramsoc.2010.01.005.

Schlur, L., A. Carton, P. Leveque, D. Guillon and G. Pourroy, 2013. Optimization of a new $\mathrm{ZnO}$ nanorods hydrothermal synthesis method for solid state dye sensitized solar cells applications. J. Phys. Chem. C, 117: 2993-3001. DOI: 10.1021/jp305787r

Tsay, C.Y., C.W. Wu, C.M. Lei, F.S. Chen and C.K. Lin, 2010. Microstructural and optical properties of Gadoped $\mathrm{ZnO}$ semiconductor thin films prepared by sol-gel process. Thin Solid Films, 519: 1516-1520. DOI: $10.1016 /$ j.tsf.2010.08.170 
Wang, Y., X. Zhang, L. Bai, Q. Huang and C. Wei et al., 2012. Effective light trapping in thin film silicon solar cells from textured $\mathrm{Al}$ doped $\mathrm{ZnO}$ substrates with broad surface feature distributions. Applied Phys. Lett., 100: 263508-263514. DOI: 10.1063/1.4731775

Xiu, F.X., L.J. Mandalapu, Z. Yang, J.L. Liu and G.F. Liu et al., 2006. Bi-induced acceptor states in $\mathrm{ZnO}$ by molecular-beam epitaxy. Applied Phys. Lett., 89: 052103-3. DOI: 10.1063/1.2243732

Zhang, J., H. Yang, Q.L. Zhang, S. Dong and J.K. Luo, 2013. Structural, optical, electrical and resistive switching properties of $\mathrm{ZnO}$ thin films deposited by thermal and plasma-enhanced atomic layer deposition. Applied Surface Sci., 282: 390-395. DOI: 10.1016/j.apsusc.2013.05.141.
Zhang, Z., C. Bao, W. Yao, S. Ma and L. Zhang et al., 2011. Influence of deposition temperature on the crystallinity of $\mathrm{Al}$-doped $\mathrm{ZnO}$ thin films at glass substrates prepared by RF magnetron sputtering method. Superlattices Microstructures, 49: 644653. DOI: $10.1016 /$ j.spmi.2011.04.002 